\title{
FORECAST RESEARCH OF CROP WATER REQUIREMENTS BASED ON FUZZY RULES
}

\author{
Jianbing Zhang ${ }^{1, *}$, Yeping $\mathrm{Zhu}^{2}$, Feixiang $\mathrm{Chen}^{3}$ \\ ${ }^{I}$ Department of Computer Science and Technology, China University of Petroleum-Beijing, \\ Beijing, China, 102249 \\ ${ }^{2}$ Institute of Agricultural Information, Chinese Academy of Agricultural Sciences, Beijing, \\ China, 100081 \\ ${ }^{3}$ College of Information, Beijing Forestry University, Beijing, China, 100083 \\ * Corresponding author, Address: Department of Computer Science and Technology, China \\ University of Petroleum-Beijing, 18 Fuxue Road, Changping, Beijing, P. R. China, 102249 \\ Tel: +86-10-89733006, Email: zhangbing153@yahoo.com.cn
}

\begin{abstract}
This paper put forward the idea of producing fuzzy rules by genetic algorithms based on Takagi-Surgeon Fuzzy Logic System from the dataset of multidimension climate data and crop water requirements, and establishing the fuzzy model to predict crop water requirements. The forecast model was tested and the result showed that it was an effective way to forecast crop water requirements by fuzzy rules model.
\end{abstract}

Keywords: Fuzzy logic system, Genetic algorithms, Crop water requirements

\section{INTRODUCTION}

The forecast of crop water requirements is importance for irrigating forecast. In order to make plans for water use in large irrigation districts, we need to predict crop water requirements and their changes in a period of time later. Many technologies had been applied in predicting for crop water requirements, such as regression analysis, gray prediction, Artificial Neural

Zhang, J., Zhu, Y. and Chen, F., 2008, in IFIP International Federation for Information Processing, Volume 259; Computer and Computing Technologies in Agriculture, Vol. 2; Daoliang Li; (Boston: Springer), pp. 1267-1273. 
Network (Renato Silvio, 1998; Zhang bing, 2000). But the results were not satisfied. Today the research of complex system has been changed from constructing precise mathematics models to constructing fuzzy models based on intelligent technology. Fuzzy logic technology is called the core technology of the 21st Century (Dou zhengzhong, 1996), it had achieved many remarkable success in industry and many high technological fields. Fuzzy logic system provides better forms of rule expression, and fuzzy technology provides reasoning logic like human thought. Genetic algorithms are adaptive heuristic search algorithm premised on the evolutionary ideas of natural selection and genetic, and they represent an intelligent exploitation of a random search within a defined search space to solve problems (Zhou Ming, 1999). Based on the combination of genetic algorithms and fuzzy logic technology, we put forward the idea of producing fuzzy rules automatically by genetic algorithms, then establishing the fuzzy model of the system. From the dataset of multi-dimension climate and crop water requirements, the fuzzy rules of crop water requirements were extracted out successfully and the model of crop water requirements and climate factors was established and tested for the forecast of crop water requirements (green pepper). The test showed better results in predicting water requirements. The method can be also used in modeling other agricultural complex system.

\section{TAKAGI-SUGENO FUZZY LOGIC SYSTEM}

Fuzzy logic systems have been successfully applied to a number of scientific and engineering problems during recent years. The expression of fuzzy rules and the reasoning in fuzzy systems are flexible. They provide flexible architecture for modeling nonlinear systems. In fact, fuzzy models are only one of mathematic expression forms of fuzzy rules and reasoning. Takagi-Surgeon Fuzzy logic systems are based on local linear function and the global nonlinear is implemented by blending the subsystems' models (Wang shitong, 1998).

The main feature of Takagi-Surgeon fuzzy models can be grouped under the form of the following steps that also point out their operating mode:

Firstly, the input space is decomposed into subspaces;

Then, within each subspace, the system model can be approximated by simpler models, in particular linear ones;

Finally, the global fuzzy model in the state-space is derived by blending the subsystems' models in terms of the weighted average of rule contributions. 
Fuzzy inference systems are composed of a set of IF-THEN rules. A TS fuzzy model has the following form of fuzzy rules:

$$
\begin{aligned}
& R^{i}: \text { IF } \quad x_{1} \text { is } A_{1}^{i}, x_{2} \text { is } A_{2}^{i}, \ldots \ldots, x_{k} \text { is } A_{k}^{i}, \\
& \text { THEN } \quad y^{i}=p_{0}^{i}+p_{1}^{i} \cdot x_{1}+\ldots+p_{k}^{i} \cdot x_{k}
\end{aligned}
$$

where $R^{i}$ means that the sequence number of rule is $\mathrm{i} ; x_{1}, x_{2}, \ldots, x_{k}$ are inputs of fuzzy system; $A_{1}^{i}, A_{2}^{i}, \ldots, A_{k}^{i}$ are fuzzy subsets, their membership function is general piecewise continuous function or Gauss function; $y^{i}$ is the output of rule $\mathrm{i} ; p_{j}^{i}(\mathrm{j}=0,1, \ldots, \mathrm{k})$ is called conclusive parameter. If there are $\mathrm{n}$ pieces of rules in the fuzzy model, and the input values is $\mathrm{X}=\left(x_{1}, x_{2}, \ldots, x_{k}\right)^{T}$, the overall output of the fuzzy model is the weighted average value of $y^{i}$ :

$$
Y=\sum_{i=1}^{m} w^{i} y^{i} / \sum_{i=1}^{m} w^{i}
$$

The computing formula of $w^{i}$ is:

$$
w^{i}=\prod_{j=1}^{k} u_{A_{j}^{i}}\left(x_{j}\right)
$$

where $u_{A_{j}^{i}}\left(x_{j}\right)$ is the membership function for fuzzy set.

\section{GENETIC ALGORITHMS}

GAs are global optimization and parallel search method. The basic concept of GAs is designed to simulate processes in natural system necessary for evolution, specifically those that follow the principles first laid down by Charles Darwin of survival of the fittest. As such they represent an intelligent exploitation of a random search within a defined search space to solve a problem.

Algorithm is started with a set of solutions (represented by chromosomes) called population. Solutions from one population are taken and used to form a new population. This is motivated by a hope, that the new population will be better than the old one. Solutions which are selected to form new solutions (offspring) are selected according to their fitness - the more suitable they are the more chances they have to reproduce. The algorithms are described as follow: 


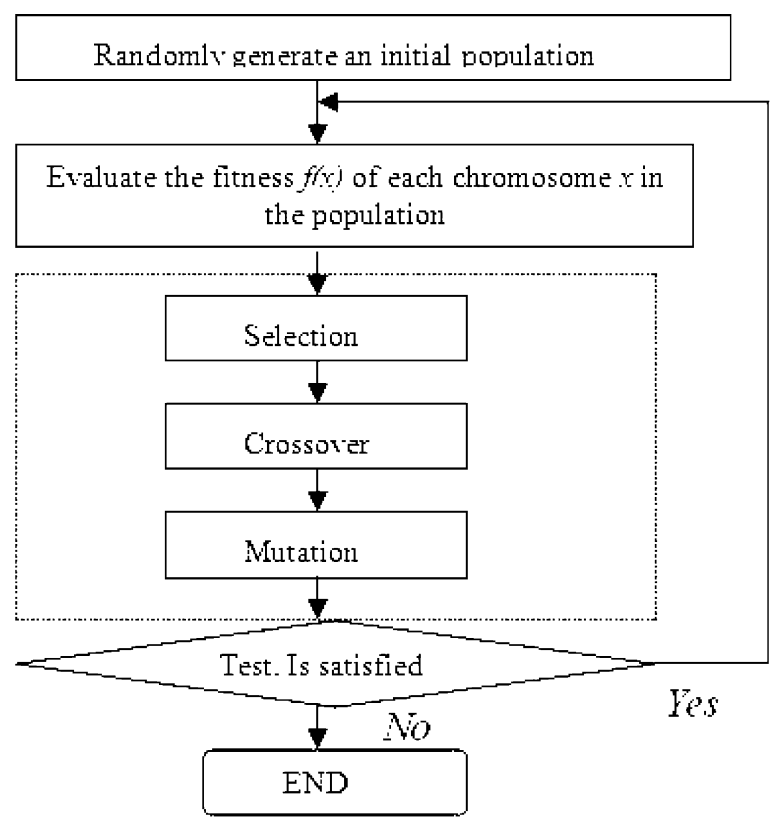

Fig. 1. The process of GA

As a computational analogy of adaptive systems, GAs are modeled loosely on the principles of the evolution via natural selection, employing a population of individuals that undergo selection in the presence of variationinducing operators such as mutation and recombination (crossover). A fitness function is used to evaluate individuals, and reproductive success varies with fitness.

GAs are used for solving parameters optimization of fuzzy logic systems. Finding the appropriate structure and parameters of fuzzy logic systems automatically is implemented by using genetic algorithms.

\section{APPLICATIONS}

A crop (green pepper) water requirements fuzzy model is established to test the method. The research data is from the reference (Renato Silvio, 1998). The dataset is the 30 continuous water requirements data, which is observed during the growth process of green pepper in 1994 (florescence). The data is filtered by regression analysis. $\mathrm{Y}$ is crop water requirements value $\left(\mathrm{mm} \cdot \mathrm{d}^{-1}\right)$; X1 is radialization data $\left(\mathrm{W} \cdot \mathrm{m}^{-2} \cdot \mathrm{d}^{-1}\right) . \mathrm{X} 2$ is value of relative humidity. The research data is shown in Table 1: 
Table 1. Crop water requirements and climate data (Year 1994)

\begin{tabular}{lccccc}
\hline Date(Month-Day) & \multicolumn{3}{c}{ Original Data } & \multicolumn{2}{c}{ Standardized Data } \\
\hline & $\mathrm{Y}$ & $\mathrm{X} 1$ & $\mathrm{X} 2$ & $\mathrm{x} 1$ & $\mathrm{x} 2$ \\
\hline $5-4$ & 1.33 & 2023 & 92.35 & 0.308409 & 1.225619 \\
$5-5$ & 3.16 & 5870 & 76.55 & 0.894890 & 1.015930 \\
$5-6$ & 3.67 & 5560 & 77.15 & 0.847630 & 1.023893 \\
$5-7$ & 1.73 & 3175 & 84.15 & 0.484033 & 1.116793 \\
$5-8$ & 4.29 & 7611 & 73.66 & 1.160308 & 0.977576 \\
$5-9$ & 4.92 & 7931 & 71.54 & 1.209092 & 0.949440 \\
$5-10$ & 4.03 & 6116 & 67.75 & 0.932393 & 0.899141 \\
$5-11$ & 5.15 & 7754 & 67.41 & 1.182108 & 0.894629 \\
$5-12$ & 4.29 & 6131 & 66.60 & 0.934680 & 0.883879 \\
$\ldots$ & $\ldots$ & $\ldots$ & $\ldots$ & $\ldots$ & $\ldots$ \\
$5-31$ & 5.43 & 8140 & 73.68 & 1.240955 & 0.977841 \\
$6-1$ & 3.98 & 6273 & 82.02 & 0.956328 & 1.088525 \\
$6-2$ & 2.86 & 4822 & 82.51 & 0.735121 & 1.095028 \\
\hline
\end{tabular}

$\mathrm{X} 1, \mathrm{X} 2$ are the results of standardized data of X1, X2. The model is established using the data from 5-4 to 5-25. The data from 5-26 to 6-2 is used for model verification. The data of $\mathrm{x} 1$ and $\mathrm{x} 2$ is used for system input, $\mathrm{Y}$ is the output of the system. The membership function is used Gaussian function $u(x)=e^{-k(x-c)^{2}}$. The forecast result of fuzzy model after training is as follow:

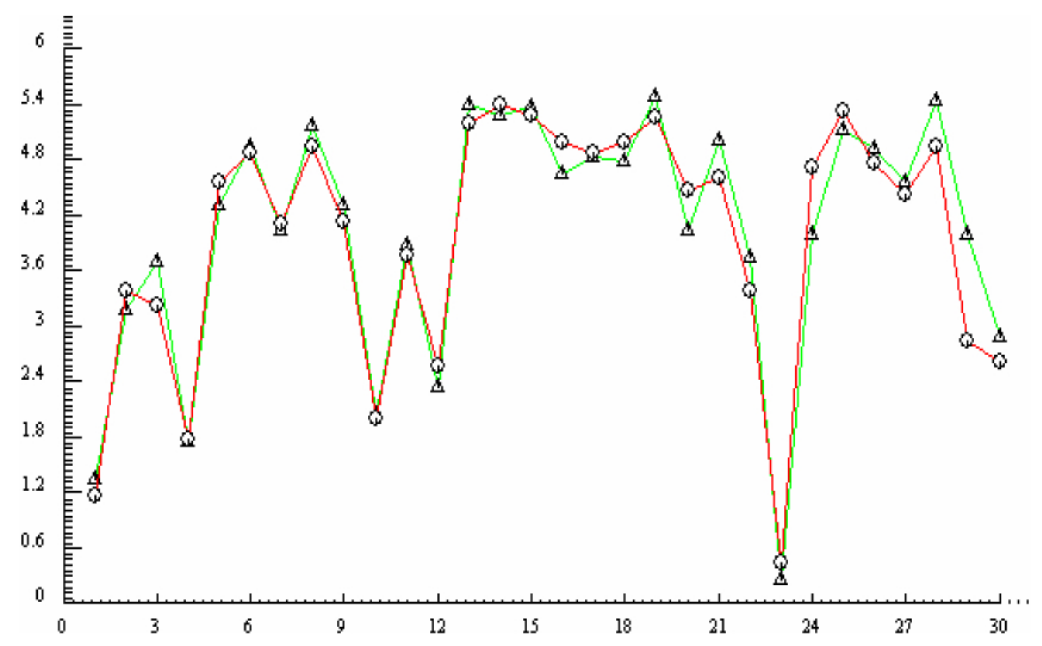

Fig. 2. The Comparison between output of model and actual data: Circle points represent actual value; triangle points represent the output of fuzzy model

The output of model is close to actual values, and most data error is less than $10 \%$. The result of 22 training data is satisfied, and the later 8 forecast result is matched with actual situation. Nine fuzzy rules are obtained by training sample data using fuzzy logic system and GAs: 
Table 2. The nine fuzzy rules

\begin{tabular}{|c|c|c|c|}
\hline $\begin{array}{l}\text { radicalization: } \\
\text { low }\end{array}$ & & $\begin{array}{l}\text { radicalization: } \\
\text { middle }\end{array}$ & $\begin{array}{l}\text { radicalization: } \\
\text { high }\end{array}$ \\
\hline $\begin{array}{l}\text { relative humidity: } \\
\text { low }\end{array}$ & $\begin{array}{l}\mathrm{Y}=0.060000^{*} \\
\mathrm{X} 2 / 75.35\end{array}$ & $\begin{array}{l}Y=0.772525 * X 1 / 6559.47+ \\
3.391403\end{array}$ & $\begin{array}{l}Y=2.138495 * X 1 / 6559.47+0.080402 * \\
\mathrm{X} 2 / 75.35+2.639984\end{array}$ \\
\hline $\begin{array}{l}\text { relative humidity: } \\
\text { middle }\end{array}$ & $Y=1.043489$ & $\begin{array}{l}\mathrm{Y}=3.479416 * \mathrm{X} 1 / 6559.47+ \\
0.239196 * \mathrm{X} 2 / 75.35\end{array}$ & $\begin{array}{l}Y=3.939482 * X 1 / 6559.47+0.049539 * \\
X 2 / 75.35\end{array}$ \\
\hline $\begin{array}{l}\text { relative humidity: } \\
\text { high }\end{array}$ & $\begin{array}{l}Y=-0.273271 * \\
X 1 / 6559.47\end{array}$ & $\begin{array}{l}Y=-8.340000 * X 1 / 6559.47+ \\
2.790065 * X 2 / 75.35+6.025024\end{array}$ & $Y=7.458415 * X 1 / 6559.47$ \\
\hline
\end{tabular}

To the research district, if radicalization and relative humidity are low, crop water requirements are direct ratio with relative humidity, $\mathrm{Y}=0.060000 * \mathrm{X} 2 / 75.35$. If radicalization is low and relative humidity is middle, $\mathrm{Y}=1.043489$. The other rules also have certain meanings. We can see that a distinct difference between the fuzzy model and forecast model of artificial neural network is that we can get fuzzy rules by using fuzzy logic system. From the result of model running, our model is established the relationships of crop water requirements and climate factors effectively based on 9 fuzzy rules, and the forecast test showed the result was satisfied. An advantage of fuzzy models is that a complex task can be done by several simple fuzzy rules.

\section{CONCLUSION}

The application of fuzzy logic system and genetic algorithms in industry is popular. While in agriculture it is seldom seen. Constructing model based on fuzzy thought is an effective way to solve modeling nonlinear system. It can imitate human thought to control complex system effectively. With the development of modern society, agricultural systems are more nonlinear, changeable and complex, the control of agriculture systems is even more difficult. By establishing fuzzy model based on fuzzy rules, we can resolve those problems of complex agricultural systems with intelligent technology. With the development of intelligent technology, the application of fuzzy model in agriculture will be popular.

\section{ACKNOWLEDGEMENTS}

This research was supported by National Scientific and Technical Supporting Programs Funded by Ministry of Science and Technology of China (2006BAD10A06), and Digital Agriculture Program of State Hightech Research and Development Project of China (No. 20060110Z2059). 


\section{REFERENCES}

Cao xianbing, Zhuang zhenquan, A method of automatically produce fuzzy rule based on genetic algorithm, Pattern recognition and artificial intelligence 1997, $10(2): 171-175$.

Dou zhengzhong, Fuzzy logic technology is core technology of 21st century, Application research of computers 1996, 13(4)8-12.

Renato Silvio da Frota Ribeiro. Fuzzy logic based automated irrigation control system optimized via neural networks [D]. American: The University of Tennessee, 1998.

Wang shitong, Neuro-Fuzzy System and its application. Beihang University Press, Beijing 1998, 6.

Zhang Bing, Yuan qishou. Model for predicting crop water requirements by using L-M optimization algorithm BP neural network. Transactions of the Chinese society of agricultural engineering 2000, 20(6): 73-76.

Zhang jianbing, Zhu yeping Forecasting research of diseases and pests based on fuzzy rules. System Sciences and Comprehensive Studies in Agriculture 2000, 16 (4): 283-285.

Zhou ming. The Theory and application of genetic algorithm. National Defence Industry Press 1999. 